\title{
Dontro LIETIETRS \\ Reversal of Diastereoselectivity in the Synthesis of Peptidomimetic 3-Carboxamide-1,4-benzodiazepin-5-ones
}

\author{
3 Pablo Pertejo, Nazaret Corres, Tomás Torroba, and María García-Valverde* \\ 4 Chemistry Department, Faculty of Science, University of Burgos, 09001 Burgos, Spain \\ 5 S Supporting Information
}
6 ABSTRACT: Enantiopure 3-carboxamide-1,4-benzodiazepin- 5-ones were synthesized via the Ugi reaction followed by the Staudinger/aza-Wittig or reduction reactions in only two steps. A complete reversal of diastereoselectivity was achieved depending on the cyclization methodology employed. The different orientation of the $\mathrm{C} 3$ substituent in our 3-substituted 1,4-benzodiazepin-5-ones with respect to the most studied 1,4- benzodiazepin-2-ones makes them complementary in the

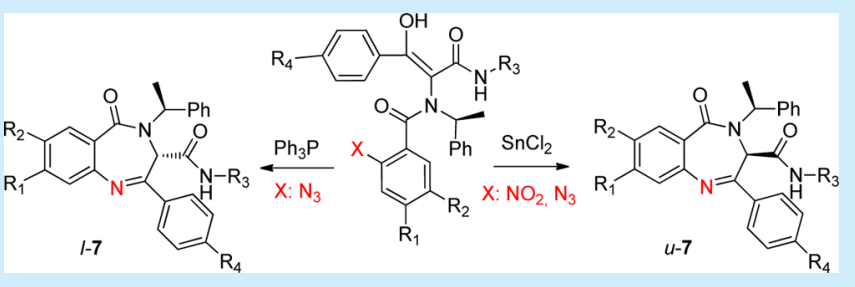 development of new drugs because the primary source of binding selectivity of 1,4-benzodiazepines is the selective recognition of ligand conformations by the receptor.

${ }_{11}^{16} \mathrm{~B}$ enzodiazepines are known as medicinally and pharmaceutically important compounds which present selective 18 activities against a diverse array of biological targets. Besides 19 their properties as psychotropic drugs (anxiolytic, ${ }^{1}$ sedative, ${ }^{2}$ or 20 anticonvulsant agents ${ }^{3}$ ), other non-psychotropic biological 21 activities have been reported such as anti-HIV properties, ${ }^{4}$ 22 antitumor antibiotics, ${ }^{5}$ and antimalarial ${ }^{6}$ or anticancer agents. ${ }^{7}$

23 Most of these benzodiazepines have in their structure one or 24 more stereogenic units, ${ }^{8}$ and even though legislative, economic, 25 and ecological pressure for the marketing of chiral molecules as 26 pure enantiomers ${ }^{9}$ has stimulated the development of cost27 effective methods for the manufacture of enantiomerically pure 28 compounds, the stereoselective synthesis of benzodiazepines 29 has received little attention. ${ }^{10}$ The methods developed for the 30 construction of chiral benzodiazepines usually imply the 31 synthesis and resolution of racemic mixtures ${ }^{11}$ or the 32 introduction of stereogenic units by using $\alpha$-amino acids from 33 the chiral pool. ${ }^{12}$

34 In previous papers, we have reported the synthesis of a new 35 family of racemic 1,4-benzodiazepines from different Ugi/ 36 cyclization sequences ${ }^{13}$ in which a new stereogenic center at the 37 C3-position was generated. Interestingly, unlike the 1,438 benzodiazepin-2-ones possessing a chiral center at the C3 39 carbon, where the conformational equilibrium was shifted 40 toward the conformer having the larger substituent in the 41 pseudoequatorial position, ${ }^{14}$ the crystal X-ray analysis of our 42 1,4-benzodiazepin-5-ones ${ }^{13 a}$ showed that the preferred con43 formation for each enantiomer was that in which the 44 substituent in C3, the amide group derived from the isocyanide 45 component in the Ugi reaction, was pseudoaxially oriented, 46 probably because of a reduced steric hindrance between this 47 group and the $\mathrm{N}^{4}$-benzyl and $\mathrm{C}^{2}$-phenyl groups. ${ }^{15}$ This, in turn, 48 restricts the conformational equilibrium in the diazepine ring, 49 and consequently, the $3 S$ stereoisomers adopt an $M$ 50 conformation and the $3 R$ stereoisomers a $P$-conformation 51 (Figure 1).

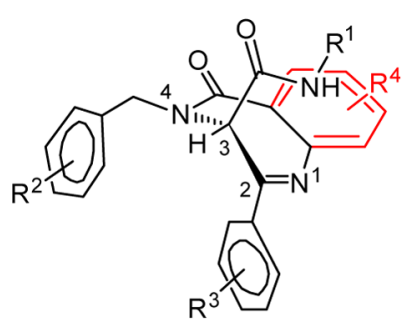

3S-(M)-conformer

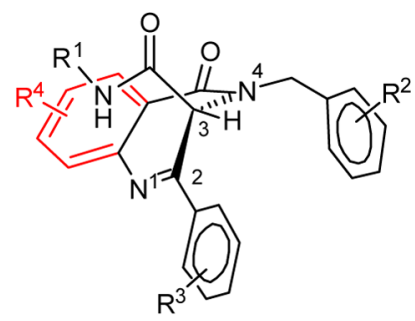

$3 R$ - $(P)$-conformer
Figure 1. Preferred conformations of 2-aryl-4-benzyl-1,4-benzodiazepin-5-ones.

The different orientation of the larger substituent in our 1,4- 52 benzodiazepin-5-ones with respect to the most studied 1,4- 53 benzodiazepin-2-ones makes them complementary in the 54 development of new drugs, as the four variations of the 55 benzodiazepine scaffold combining the ring conformation and 56 the orientation of the larger substituent in $\mathrm{C} 3{ }^{16}$ could be 57 controlled according to the family chosen. It has been 58 suggested that the primary source of 1,4-benzodiazepine's 59 binding selectivity is the selective recognition of ligand 60 conformations by the receptor. ${ }^{17}$ Consequently, by controlling 61 the configuration at $\mathrm{C} 3$ of these constrained benzodiazepines, 62 we could control their conformation and therefore their 63 activity. In this way, we found selective fitting of our 64 constrained benzodiazepines with different $\beta$-turn motifs 65 depending on their conformation and hence on the C3 66 configuration. Thus the $3 R$ enantiomer superimposes well on 67 the two central amino acid backbones of type I $\delta$-antigen and 68 type II' $^{\prime}$ erabutoxin B (Figure 2), while the $3 S$ enantiomer $69 \mathrm{f} 2$ perfectly fits with the $\beta$-turn motifs of type $\mathrm{I}^{\prime}$ of acetyl CoA $70 \mathrm{f3}$

Received: December 16, 2014 
f3 $\quad 71$ carboxylase and type II of LDL receptor module 5 (Figure $723)^{13 a}$ (a)

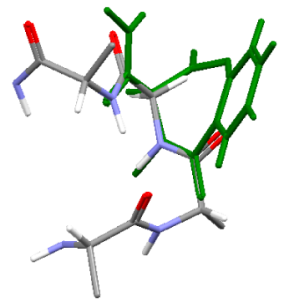

(b)

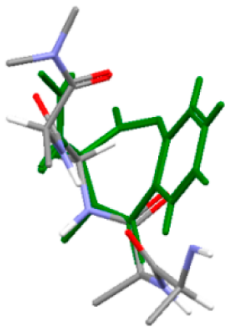

Figure 2. Superimposition of the $3 R$ enantiomer to a peptide backbone of (a) type I $\beta$ and (b) type II' $\beta$-turn motifs. (a)

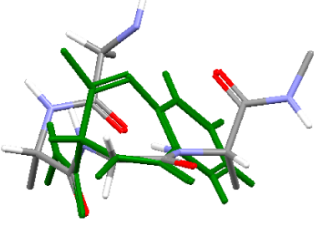

(b)

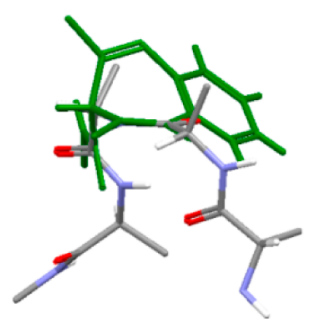

Figure 3. Superimposition of the $3 S$ enantiomer to a peptide backbone of (a) type I' $\beta$ and (b) type II $\beta$-turn motifs.

73 Due to the relevance of this behavior, we thought about 74 developing the stereoselective synthesis of $3 H$-benzo[e][1,4]75 diazepin-5 $(4 H)$-ones. To that end, we relied on the 76 tautomerism observed in our previously described strategies. 77 On the one hand, the Ugi $\alpha$-amido- $\beta$-ketoamide intermediates 78 obtained by these methodologies were exclusively in the enol form with no trace of the keto tautomer observed. ${ }^{13 a}$ On the 79 other hand, when an oxo group was present at the 5-position in 80 the $3 H$-benzo[ $e][1,4]$ diazepine system, the imine tautomer was 81 the only form observed. ${ }^{13 b}$ Thus, although a new stereogenic 82 center was usually generated in the Ugi reaction, the preferred 83 enol form obtained using these methodologies would prevent 84 its formation in this stage, leading to prochiral $\mathrm{sp}^{2}$ carbons. This 85 constitutes an advantage because the stereoselectivity in the Ugi 86 reaction is usually poor. ${ }^{11 \mathrm{c}}$ Meanwhile, the preferred imine 87 tautomer in the $3 H$-benzo[e][1,4]diazepin-5 $(4 H)$-ones gen- 88 erated in the second stage would lead to stereogenic centers in 89 the C3-position so that generation could be controlled in the 90 cyclization step.

Therefore, we tried the stereoselective synthesis of our 92 benzodiazepines using commercially available enantiopure $(S)-93$ $(-)-\alpha$-methylbenzyl amine 4 as the chiral component. The 94 chosen Ugi/cyclization strategy determined the nature of the 95 carboxylic acid used in the Ugi reaction. In this way, some 2- 96 azidobenzoic acids (1a-d) synthesized from the corresponding 97 anthranilic acid derivative and sodium azide ${ }^{18}$ were used in the 98 Ugi/Staudinger/aza-Wittig sequence, while commercially avail- 99 able 2-nitrobenzoic acid derivatives $(\mathbf{1 e - g})$ were used in the 100 Ugi/reduction cyclization sequence (Scheme 1).

$101 \mathrm{~s} 1$

The Ugi reaction was carried out in a similar way in both 102 sequences following the usual procedure. ${ }^{19}$ Therefore, the 103 corresponding imine was preformed by mixing the $(S)-(-)-\alpha-104$ methylbenzyl amine $4^{20}$ (1 equiv) with a solution of 105 arylglyoxals $^{21} \mathbf{3 a - c}$ (1 equiv) in methanol. Alkyl isocyanides 106 $\mathbf{2 a}, \mathbf{b}$ ( 1 equiv) and the corresponding benzoic acids $\mathbf{1 a}-\mathbf{g}\left(\begin{array}{ll}1 & 107\end{array}\right.$ equiv) were then added to the imine solution, and the mixture 108 was stirred at room temperature for one day until precipitation 109 of Ugi products. Filtration of solids afforded the Ugi adducts 110 (azides 5a-d and nitro derivatives 6a-f). As expected, the only 111 tautomer observed by NMR spectra of these Ugi adducts was $112 \mathrm{tl}$

Scheme 1. Syntheses of Benzodiazepines from 2-Azides 1a-d and 2-Nitrobenzoic Acids 1e-g

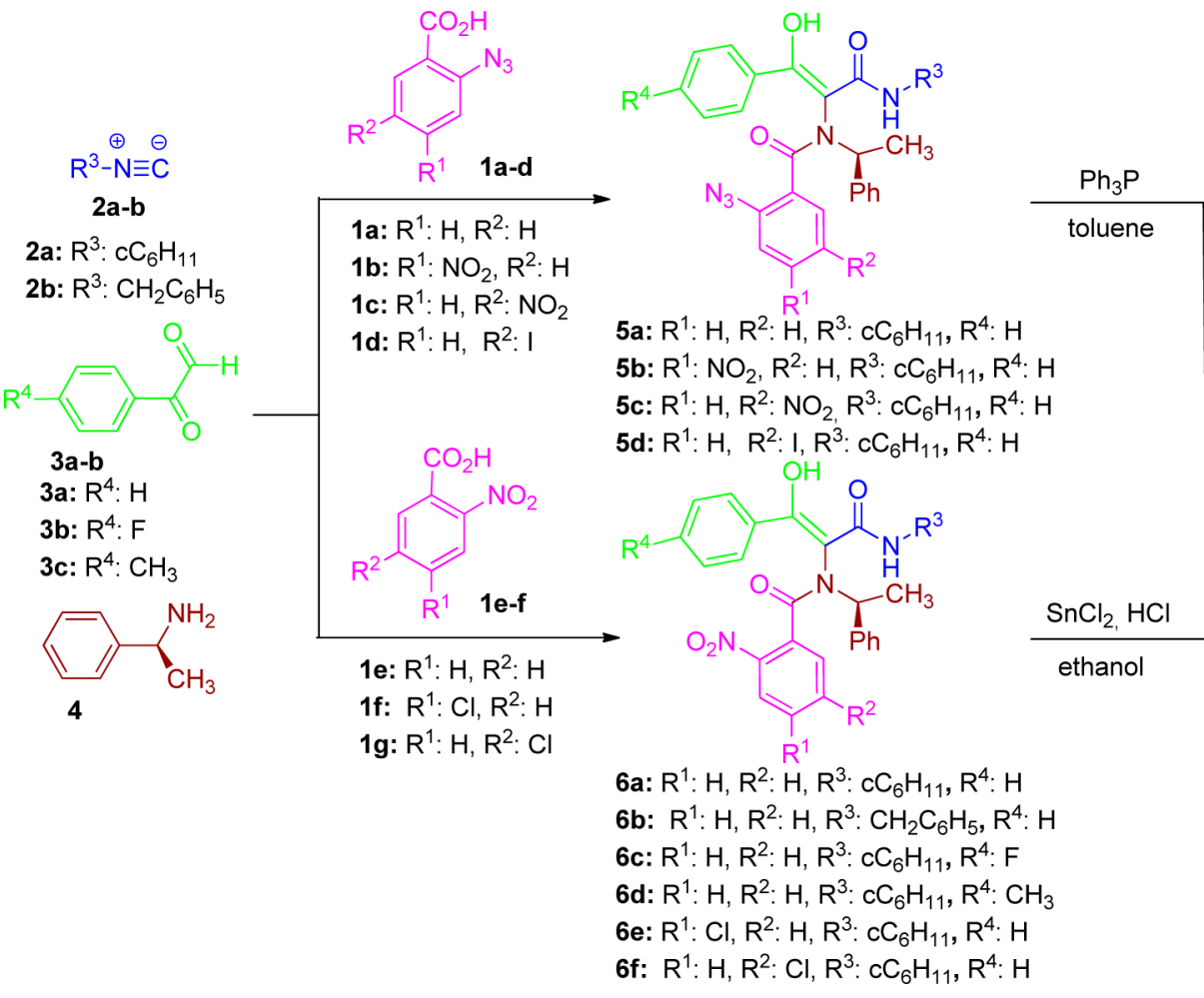


113 the enol form (as a conformer mixture) (Scheme 1 and Table $1141)$.

Table 1. Diastereoselective Synthesis of 1,4-Benzodiazepin5-ones from Ugi/Cyclization Sequences

\begin{tabular}{|c|c|c|c|c|c|c|}
\hline entry & 1 & 2 & 3 & $5 / 6^{a}(\%)$ & $7(\%)^{b}$ & $\mathrm{dr}^{c}(l: u)^{d}$ \\
\hline 1 & $1 \mathrm{a}$ & $2 a$ & $3 a$ & 5a (69) & $7 \mathbf{a}^{f}(80)$ & $84: 16^{e}$ \\
\hline 2 & $1 b$ & $2 a$ & $3 a$ & $5 \mathbf{b}(61)$ & $7 \mathbf{b}^{f}(65)$ & $70: 30$ \\
\hline 3 & $1 c$ & $2 a$ & $3 a$ & $5 c(65)$ & $7 \mathbf{c}^{f}(71)$ & $81: 19$ \\
\hline 4 & $1 d$ & $2 a$ & $3 a$ & $5 d(72)$ & $7 \mathbf{d}^{f}(88)$ & 90:10 \\
\hline 5 & 1e & $2 a$ & $3 a$ & 6a $(80)$ & $7 a^{g}(87)$ & $5: 95^{e}$ \\
\hline 6 & le & $2 b$ & $3 a$ & $\mathbf{6 b}(70)$ & $7 e^{g}(83)$ & 7:93 \\
\hline 7 & 1e & $2 a$ & $3 b$ & 6c (75) & $7 f^{g}(85)$ & 4:96 \\
\hline 8 & 1e & $2 a$ & $3 c$ & 6d (75) & $7 \mathrm{~g}^{g}(88)$ & 1:99 \\
\hline 9 & If & $2 a$ & $3 a$ & 6e (73) & $7 h^{g}(86)$ & 3:97 \\
\hline 10 & $1 \mathrm{~g}$ & $2 a$ & $3 a$ & 6f $(76)$ & $7 \mathbf{i}^{g}(88)$ & 2:98 \\
\hline
\end{tabular}

${ }^{a}$ Ugi adducts are obtained exclusively as enol tautomers, as shown by NMR spectra. ${ }^{b}$ Isolated yields for the major diastereomer. ${ }^{c}$ Determined by ${ }^{1} \mathrm{H}$ NMR analysis of the crude reaction mixtures. ${ }^{d}$ The $l(\alpha S, 3 S): u(\alpha S, 3 R)$ assigned on the basis of X-ray diffraction of major isomer of 7 e. ${ }^{e}$ Identical ratio is obtained using $(R)-\alpha$ methylbenzyl amine as chiral source $(l(\alpha R, 3 R): u(\alpha R, 3 S)) .{ }^{f}$ Following the Staudinger/aza-Wittig methodology. ${ }^{g}$ Following the reduction/ cyclization methodology.

115 The obtained Ugi adducts were then subjected to the 116 appropriate conditions in order to achieve the cyclization to 117 benzodiazepines. Thus, the chiral azide Ugi adducts $\mathbf{5 a}-\mathbf{d}$ (1 118 equiv) were treated under optimized Staudinger/aza-Wittig 119 conditions $^{13 a}$ using triphenylphosphine (1.5 equiv) under a 120 nitrogen atmosphere in toluene for $24 \mathrm{~h}$ at room temperature. 121 Conversely, chiral nitro Ugi adducts $\mathbf{6 a}-\mathbf{f}$ were treated in the 122 optimized chemical conditions found for the achiral sub123 strates, ${ }^{13 \mathrm{~b}}$ by using stannous chloride (10 equiv) as reductant in 124 the presence of hydrochloric acid (3 equiv) in ethanol for 45 $125 \mathrm{~min}$ at reflux. A range of different substituents participated 126 efficiently in these reactions, yielding the desired 1,4127 benzodiazepin-5-ones $7 \mathbf{a}-\mathbf{i}$ with high chemical yields. These 128 synthetic methods easily led to $\mathrm{C} 7 / \mathrm{C} 8$-substituted 1,4129 benzodiazepines $\left(\mathrm{R}^{1}, \mathrm{R}^{2}: \mathrm{NO}_{2}, \mathrm{Cl}, \mathrm{I}\right)$, which could be easily 130 functionalized to generate chemical diversity (Scheme 1 and 131 Table 1).

132 From a stereochemical point of view, as it was expected that 133 the imine was the only observed tautomer, and therefore, a new 134 stereogenic center was generated in the cyclization step. The 135 cyclization took place in a stereoselective way, with moderate to 136 excellent diastereoselectivity, as determined by ${ }^{1} \mathrm{H}$ NMR 137 analysis of the crude reaction mixtures ${ }^{22}$ (Table 1). The 138 diastereomers could be easily separated by column chromatog139 raphy or recrystallization, affording enantiopure benzodiaze140 pines.

141 The degree of diastereoselectivity achieved in the reduction/ 142 intramolecular cyclization tandem reaction from nitro-Ugi 143 adducts was higher than that achieved with the Staudinger/ 144 aza-Wittig methodology from the azide derivatives (Table 1, 145 entry 5 vs 1 ), with almost complete diastereoselectivity for the 146 former (Table 1, entries 5-10). Although these stereochemical 147 results are highly positive, a much more remarkable aspect is 148 the sense of stereoselectivity achieved in each case because a 149 complete reversal of diastereoselectivity was observed depend150 ing on the cyclization methodology employed.
A single crystal of the major isomer of $7 \mathbf{e}$ obtained in the Ugi 151 reduction sequence (Table 1 , entry 6) allowed X-ray diffraction 152 analysis identification of its absolute configuration as $(\alpha S, 3 R), 153$ with the expected $P$-conformation of benzodiazepine (Figure $154 \mathrm{f} 4$ 4). This result, coupled with the ${ }^{1} \mathrm{H}$ NMR spectra, allowed the $155 \mathrm{f} 4$

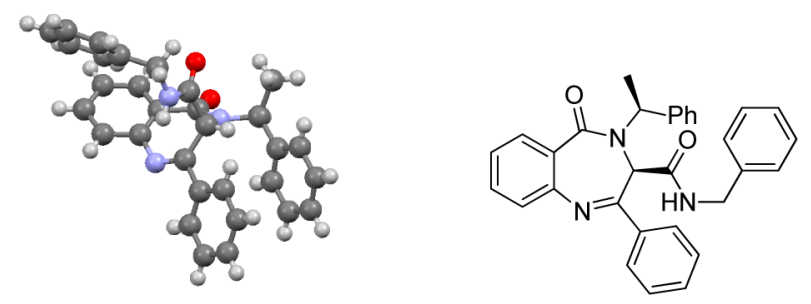

Figure 4. X-ray diffraction structure of 1,4-benzodiazepin-3one $(\alpha S, 3 R)-7 \mathbf{e}$, the major isomer in the Ugi/reduction sequence.

assignment of absolute configuration of the new benzodiaze- 156 pines synthesized. On the one hand, the proton signal at C3 157 around $5 \mathrm{ppm}$ confirms the pseudoaxial arrangement of the 158 larger substituent, and the axial disposition of the C3 proton 159 would shift this signal to a lower chemical shift due to the 160 shielding cone of the benzene ring. ${ }^{23}$ On the other hand, the 161 signal of this proton in the unlike stereoisomer appears at a 162 lower frequency (around $0.2 \mathrm{ppm}$ ) than the same proton in the 163 like stereoisomer.

164

We observed that the reduction of the nitro-Ugi adduct 165 followed by intramolecular cyclization produced the 1,4- 166 benzodiazepin-5-ones with an $\alpha, 3$-unlike stereochemical 167 relationship, while the Ugi/Staudinger/aza-Wittig sequence 168 afforded a like relative configuration.

The different reaction mechanism for each cyclization 170 methodology employed could explain the different stereo- 171 chemical outcomes in each case, a tandem $[2+2] 172$ cycloaddition between the phosphazene and the carbonyl 173 group in the aza-Wittig reaction ${ }^{24}$ and a nucleophilic ${ }^{25}$ or 174 radical $^{26}$ addition of the nitrogen to the C3-position of the 175 acrylamide enol Ugi adduct in the reduction cyclization 176 sequence. Trying to confirm that, we decided to reduce the 177 azide group using a similar methodology to that employed in 178 the reduction of the nitro group. Thus, a mixture of azide Ugi 179 adduct 5a ( 1 equiv) and stannous chloride ( 1.5 equiv) in 180 ethanol was stirred at room temperature for $1 \mathrm{~h}$ to yield the 181 benzodiazepine $7 a^{27}$ The reduction took place efficiently 182 (chemical yield of 74\%), and as expected, the stereochemical 183 result was similar to that obtained with the nitro derivative with 184 the same sense (unlike relative configuration), although worse 185 diatereoselectivity (15:85 vs 5:95), supporting the importance 186 of the cyclization methodology chosen.

Thus, although the Ugi reduction methodology has some 188 chemical advantages over the Ugi/Staudinger/aza-Wittig (more 189 ecofriendly, simple, and scalable methodology), from a 190 stereochemical point of view, both methods are complemen- 191 tary. Depending on the preferred configuration of C3 and, 192 therefore, on the preferred conformation of the benzodiazepine 193 system, the methodology employed should be different. 194

In conclusion, we have demonstrated the versatility of the 195 Ugi/postcondensation sequence in the synthesis of enantiopure 196 1,4-benzodiazepin-3-ones. The configuration of the new 197 stereogenic center could be controlled by the methodology 198 employed because the diastereoselectivity of the reaction is 199 highly dependent on the cyclization step. The importance of 200 these methodologies is illustrated by the selective super- 201 
202 imposition of benzodiazepine enantiomers with $\beta$-turn motifs 203 (types I and $\mathrm{II}^{\prime}$ for $3 R$ stereoisomers and types I' and II for $3 S$ 204 stereoisomers), which makes these complementary stereo205 selective methods potentially useful in the development of new 206 drugs.

\section{ASSOCIATED CONTENT}

\section{S Supporting Information}

209 Experimental procedures, characterization data, ${ }^{1} \mathrm{H}$ and ${ }^{13} \mathrm{C}$ 210 NMR spectra and X-ray data. This material is available free of 211 charge via the Internet at http://pubs.acs.org.

\section{$212 \square$ AUTHOR INFORMATION}

\section{Corresponding Author}

214 *E-mail: magaval@ubu.es.

215 Notes

216 The authors declare no competing financial interest.

\section{ACKNOWLEDGMENTS}

218 We gratefully acknowledge financial support from the Minister219 io de Economía y Competitividad, Spain (Project CTQ2012220 31611), Junta de Castilla y León, Consejería de Educación y 221 Cultura y Fondo Social Europeo (Project BU246A12-1) and 222 the European Commission, Seventh Framework Programme 223 (Project SNIFFER FP7-SEC-2012-312411). We also thank 224 Marta Mansilla and Dr. Jacinto J. Delgado (SCAI-Universidad 225 de Burgos) for the X-ray determinations.

\section{$226 \square$ REFERENCES}

227 (1) Davidson, J. R. J. Clin. Psychiatry 2001, 62, 46.

228 (2) McCall, W. V. J. Clin. Psychiatry 2001, 62, 27.

229 (3) Richter, L.; De Graaf, C.; Sieghart, W.; Varagic, Z.; Mörzinger, 230 M.; De Esch, I. J. P.; Ecker, G. F.; Ernst, M. Nat. Chem. Biol. 2012, 8, 231455.

232 (4) Hsu, M.-C.; Schutt, A. D.; Holly, M.; Slice, L. W.; Sherman, M. I.; 233 Richman, D. D.; Potash, M. J.; Volsky, D. J. Science 1991, 254, 1799.

234 (5) Thurston, D. E.; Bose, D. S. Chem. Rev. 1994, 94, 433.

235 (6) Nallan, L.; Bauer, K. D.; Bendale, P.; Rivas, K.; Yokoyama, K.; 236 Hornéy, C. P.; Pendyala, P. R.; Floyd, D.; Lombardo, L. J.; Williams, 237 D. K.; Hamilton, A.; Sebti, S.; Windsor, W. T.; Weber, P. C.; Buckner, 238 F. S.; Chakrabarti, D.; Gelb, M. H.; Van Voorhis, W. C. J. Med. Chem. 239 2005, 48, 3704.

240 (7) (a) Hunt, J. T.; Ding, C. Z.; Batorsky, R.; Bednarz, M.; Bhide, R.; 241 Cho, Y.; Chong, S.; Chao, S.; Gullo-Brown, J.; Guo, P.; Kim, S. H.; 242 Lee, F. Y. F.; Leftheris, K.; Miller, A.; Mitt, T.; Patel, M.; Penhallow, B. 243 A.; Ricca, C.; Rose, W. C.; Schmidt, R.; Slusarchyk, W. A.; Vite, G.; 244 Manne, V. J. Med. Chem. 2000, 43, 3587. (b) Sundberg, T. B.; Ney, G. 245 M.; Subramanian, C.; Opipari, A. W.; Glick, G. D. Cancer Res. 2006, 246 66, 1775. (c) Dourlat, J.; Liu, W.; Greash, N.; Garbay, C. Bioorg. Med. 247 Chem. Lett. 2007, 17, 2527.

248 (8) (a) Parker, K. A.; Coburn, C. A. J. Org. Chem. 1992, 57, 97. 249 (b) Cooper, N.; Hagan, D. R.; Tiberghien, A.; Ademefun, T.; 250 Matthews, C. S.; Howard, P. W.; Thurston, D. E. Chem. Commun. 251 2002, 1764. (c) Ettmayer, P.; Chloupek, S.; Weigand, K. J. Comb. 252 Chem. 2003, 5, 253. (d) Araújo, A. C.; Rauter, A. P.; Nicotra, F.; 253 Airoldi, C.; Costa, B.; Cipolla, L. J. Med. Chem. 2011, 54, 1266.

254 (9) Ma, S. K.; Gruber, J.; Davis, C.; Newmann, L.; Gray, D.; Wang, 255 A.; Grate, J.; Huisman, G. W.; Sheldon, R. A. Green Chem. 2010, 12, 25681 .

257 (10) Penhoat, M.; Bohn, P.; Dupas, G.; Papamicaël, C.; Marsais, F.; 258 Levacher, V. Tetrahedron: Asymmetry 2006, 17, 281.

259 (11) (a) Reider, P. J.; Davis, P.; Hughes, D. L.; Grabowski, E. J. J. J. 260 Org. Chem. 1987, 52, 955. (b) Bock, M. G.; DiPardo, R. M.; Evans, B. 261 E.; Rittle, K. E.; Veber, D. F.; Freidinger, R. M.; Hirshfield, J.; Springer, 262 J. P. J. Org. Chem. 1987, 52, 3232. (c) Leonard, K.; Marugan, J. J.;
Raboisson, P.; Calvo, R.; Gushue, J. M.; Koblish, H. K.; Lattanze, J.; 263 Zhao, S.; Cummings, M. D.; Player, M. R.; Maroney, A. C.; Lu, T. 264 Bioorg. Med. Chem. Lett. 2006, 16, 3463. (d) Akgün, E.; Körner, M.; 265 Gao, F.; Harikumar, K. G.; Waser, B.; Reubi, J. C.; Portoghese, P. S.; 266 Miller, L. J. J. Med. Chem. 2009, 52, 2138. (e) Andronati, S.; 267 Semenishyna, E.; Pavlovsky, V.; Simonov, Y.; Makan, S.; Boyko, I.; 268 Burenkova, N.; Gdaniec, M.; Cardinael, P.; Bouillon, J.-P.; Mazepa, A. 269 Eur. J. Med. Chem. 2010, 45, 1346.

(12) (a) Carabateas, P. M.; Harris, L. S. J. Med. Chem. 1966, 9, 6. 271 (b) Schultz, A. G.; McCloskey, P. J.; Court, J. J. J. Am. Chem. Soc. 272 1987, 109, 6493. (c) Antonow, D.; Thurston, D. E. Chem. Rev. 2011, 273 111,2815

(13) (a) Sañudo, M.; García-Valverde, M.; Marcaccini, S.; Delgado, 275 J.; Rojo, J.; Torroba, T. J. Org. Chem. 2009, 74, 2189. (b) Pertejo, P.; 276 García-Valverde, M.; Peña, P.; Cordero, N. A.; Torroba, T.; González- 277 Ortega, A. Org. Biomol. Chem. 2014, 12, 4905.

(14) (a) Šunjić, V.; Lisini, A.; Sega, A.; Kovač, T.; Fajfež, F.; Ruščić, 279 B. J. Heterocycl. Chem. 1979, 16, 757. (b) Simonyi, M.; Maksay, G.; 280 Kovács, I.; Tegyey, Z.; Párkányi, L.; Kálmán, A.; Ötvös, L. Bioorg. 281 Chem. 1990, 18, 1. (c) Paizs, B.; Simonyi, M. Chirality 1999, 11, 651. 282

(15) Preliminary studies show the importance of the $N^{4}$ benzyl group 283 in the pseudoaxial orientation of the $\mathrm{C} 3$ substituent. Computational 284 studies about the influence of the $N^{4}$ substitution in the conforma- 285 tional equilibrium are currently in progress. 286

(16) Hata, M.; Marshall, G. R. J. Comput.-Aided Mol. Des. 2006, 20, 287 321. 288

(17) Fitos, I.; Visy, J.; Zsila, F.; Mády, G.; Simonyi, M. Bioorg. Med. 289 Chem. 2007, 15, 4857.

(18) Budruev, A. V.; Karyakina, L. N.; Levina, O. P.; Oleinik, A. V. 291 Russ. J. Coord. Chem. 2005, 31, 181.

(19) Marcaccini, S.; Torroba, T. Nat. Protoc. 2007, 2, 632.

(20) The most economical and simple primary chiral amine, $(S)-\alpha-294$ methylbenzyl amine, has been chosen as chiral source, although some 295 additional experiments have been carried out using the $R$ enantiomer. 296 (21) Eftekhari-Sis, B.; Zirak, M.; Akbari, A. Chem. Rev. 2013, 113, 297 2958.

(22) See Supporting Information for details.

(23) Salvadori, P.; Bertucci, C.; Ascoli, G.; Uccelo-Barretta, G.; Rossi, 300 E. Chirality 1997, 9, 495.

(24) (a) Cossio, F. P.; Alonso, C.; Lecea, B.; Ayerbe, M.; Rubiales, 302 G.; Palacios, F. J. Org. Chem. 2006, 71, 2839. (b) Riedrich, M.; Harkal, 303 S.; Arndt, H.-D. Angew. Chem., Int. Ed. 2007, 46, 2701.

(25) Calow, A. D. J.; Carbó, J. J.; Cid, J.; Fernández, E.; Whiting, A. J. 305 Org. Chem. 2014, 79, 5163.

(26) The radical addition is a plausible mechanism which could 307 explain the different stereochemical result. Some references about 308 nitrogen-centered radical reactions: (a) Zard, S. Z. Chem. Soc. Rev. 309 2008, 37, 1603. (b) Musacchio, A. J.; Nguyen, L. Q.; Beard, G. H.; 310 Knowles, R: R. J. Am. Chem. Soc. 2014, 136, 12217. 311

(27) Maiti, S. N.; Singh, M. P.; Micetich, R. G. Tetrahedron Lett. 312 1986, 27, 1423. 